\title{
O TRABALHO E AS ORGANIZAÇÕES NA PERSPECTIVA SÓCIO-TÉCNICA
}

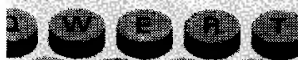

230

$300 \times$

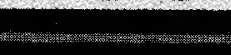

ARTIGO

* Fábio de Biazzi Jr.

A conveniência e a viabilidade da implementação do enfoque sócio-técnico nas empresas.

The convenience and the viability of sociotechnical approach in firms.

PALAVRAS-CHAVE:

Sistemas sócio-técnicos, organização do trabalho, projeto do trabalho.

KEY WORDS:

Sociotechnical systems, work organization, job design.

Engenheiro de Produção e Mestre em Engenharia de Produção pela POLI/USP, Doutorando do Departamento de Psicologia Social do Instituto de Psicologia da USP.

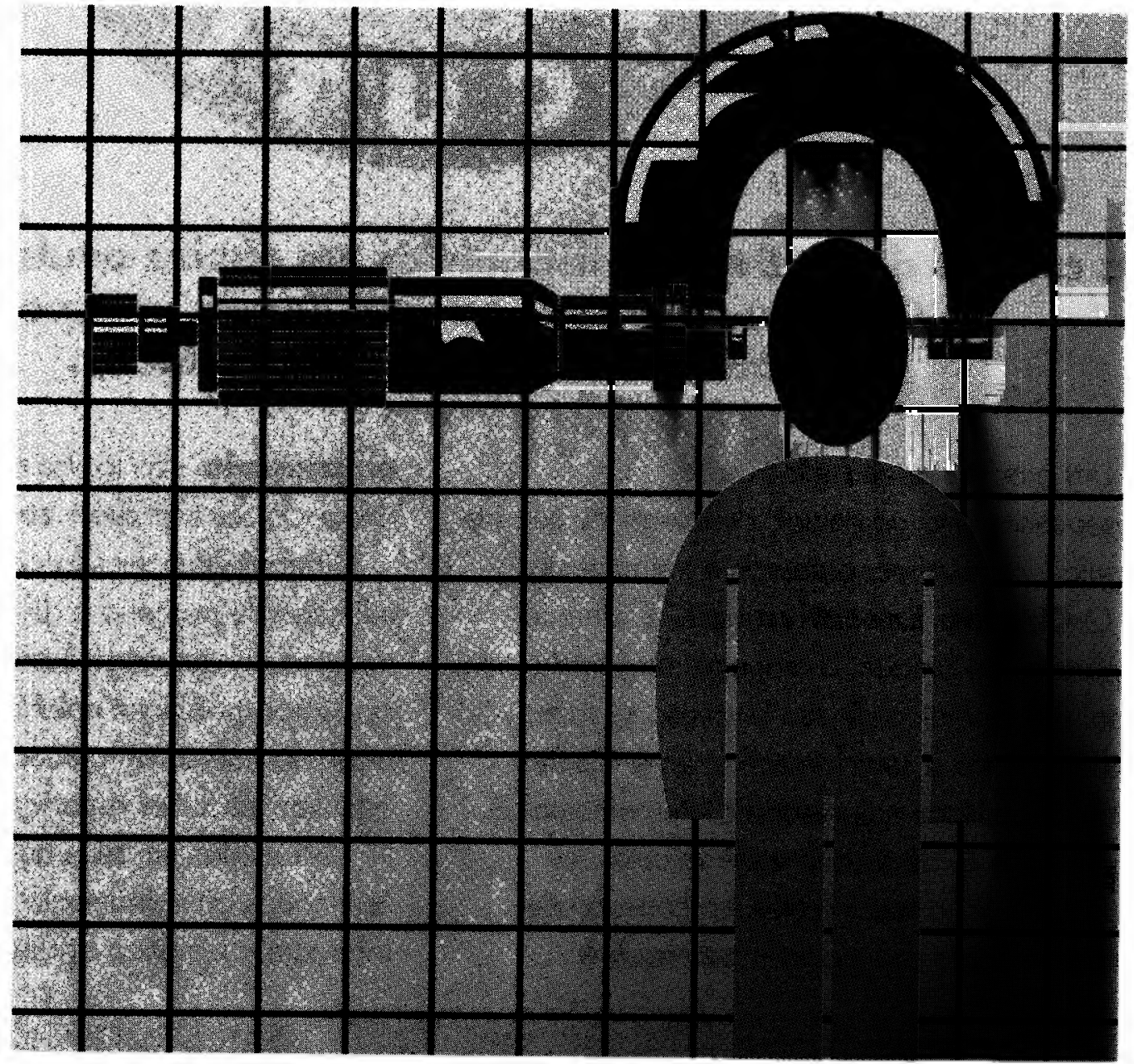




\section{A ORIGEM DA ESCOLA SÓCIO-TÉCNICA}

A história da Escola Sócio-Técnica começa junto às minas de carvão de Durham, ao norte da Inglaterra, em 1949, quando alguns pesquisadores do então recém-criado Tavistock Institute of Human Relations foram chamados para analisar os problemas relativos à mecanização dos processos de mineração.

$O$ processo de mineração, desde seu surgimento nos séculos XII e XIII, praticamente não havia sofrido modificações significativas até então. Os mineiros realizavam seus trabalhos em duplas, um dos quais podia ser um aprendiz. As ferramentas eram manuais e o trabalho extremamente desgastante. A dupla era formada por escolha pessoal e executava todo o ciclo de operações de extração. Trabalhavam em locações dispersas e autoselecionadas dos veios carboníferos - que são como lâminas de 1 a 3 metros de espessura entre placas de rochas e que podem se situar a centenas de metros de profundidade. Trabalhavam sem supervisão e eram pagos pelo trabalho da dupla. Esses mineiros possuíam um profundo conhecimento da mina e das condições de trabalho. ${ }^{1}$ Esta forma de trabalho era denominada hand-got system.

A mecanização das minas inglesas se deu pela introdução de um método de extração chamado longwall method, numa tradução direta, "método de paredes longas". De acordo com este método, um veio carbonífero é extraído em faces que constituíam uma parede de cerca de 200 metros de largura. À medida que a parede avança e todo o carvão é retirado, o teto da área livre deixada para trás é feito desabar, criando condições seguras para a progressão da parede longa. Este novo método exigia pesados investimentos em maquinaria, como cortadores, furadeiras e esteiras transportadoras. Para trabalhar com essas máquinas, os mineiros foram separados em tarefas especializadas, que exigiam diferentes níveis de habilidade $\mathbf{e}$ eram remunerados por diferentes sistemas de pagamento.

Cada parede longa era trabalhada por um total de quarenta homens, que compunham sete grupos especializados, operando quatro destes grupos em um primeiro turno, dois no segundo e um no terceiro. As tarefas específicas consistiam em fazer furos e cortes no veio, abrir galerias, transportar o carvão, montar e desmontar a esteira rolante e fazer o teto desabar. A introdução do longwall method não trouxe o aumento de produtividade esperado, fez com que as taxas de absenteísmo e rotatividade se elevassem e criou uma incidência epidêmica de desordens psicossomáticas entre os mineiros. ${ }^{2}$

Esse trabalho de extração de carvão foi então analisado cuidadosamente por Eric L. Trist e Kenneth W. Bamforth. Dado o caráter multidisciplinar do Tavistock, baseado principalmente em Psicologia e Sociologia, esta análise buscou descrever e inter-relacionar os aspectos técnicos, organizacionais, sociais e psicológicos do trabalho de extração realizado sob o método de paredes longas. Dessa forma, foi cunhado, pela primeira vez, um exemplar do que podemos chamar de "análise sócio-técnica". Este trabalho foi publicado em 1951: ${ }^{3}$

Poucos anos mais tarde, a continuação dos estudos nas minas de carvão fez com que esses pesquisadores presenciassem uma outra experiência fundamental para as bases da Escola Sócio-Técnica. Retornando às minas de Durham, Eric L. Trist e seus colaboradores encontraram, na aldeia de Chopwell, as mesmas técnicas e máquinas do método de paredes longas organizadas diferentemente. $\mathrm{O}$ método utilizado nesta mina era denominado composite longwall method, numa tradução direta, "método composto de paredes longas". Consistia no rearranjo do mesmo grande grupo de quarenta homens em subgrupos interdependentes ao longo dos turnos. Assim, cada mineiro executava funções internamente alocadas em subgrupos que desempenhavam todas as tarefas relativas à extração do carvão. As equipes dos turnos seguintes iniciavam o trabalho onde as anteriores haviam terminado. Todos recebiam o mesmo salário e incentivos, sendo o pagamento definido pela produção do grupo como um todo. Estes grupos eram significativamente autônomos e alternavam papéis e turnos com um mínimo de supervisão. ${ }^{4}$

A existência dessa forma de organização constituía uma ruptura em relação à tendência de um maior fracionamento de tarefas e burocratização que se julgava
1. MURRAY, H. Uma Introdução aos Sistemas Sócio-Técnicos ao Nível do Grupo de TrabaIho Primário. São Paulo: EAESP/FGV, 1977 (apostila).

2. HERBST, P. G. Sociotechnical design: strategies in multidisciplinary research. Londres: Tavistock, 1974.

3. TRIST, E. L., BAMFORTH, K. $W$. Some social and psychological consequences of the longwall method of coal-getting. Human Relations, v.4, n.1, p.338,1951 .

4. MURRAY, H. Op. cit. 
5. BERTALANFFY, L. Von . The theory of open systems in physics and biology. In: EMERY, F. E. Systems thinking. Londres: Penguin Books, 1969.

6. BION, W. R. Experiências com grupos. São Paulo: ImagoEdusp, 1975; JAQUES, E. Socia systems as a defense against persecutory and depressive anxiety. In: KLEIN, M., HEIMANN, P., MONEY-KYRLE, R. E. New directions in psychoanalysis. Londres: Tavistock, 1955; LEWIN, K. Problemas de dinámica de grupo. São Paulo: Cultrix, 1987.

7. TRIST, E. L. The Evolution of Sociotechnical Systems. Documento n. 2, Ontario Quality of Working Life Center, junho, 1981.

8. MURRAY, H. Op. cit. indissoluvelmente ligada à crescente mecanização e à evolução tecnológica e organizacional. $\mathrm{O}$ método composto de paredes longas combinava a mecanização com as principais características do artigo hand-got system, das duplas de mineiros.

Deste modo, surge o conceito de escolha organizacional. Uma dada organização de trabalho não é decorrente apenas da tecnologia utilizada, mas depende, além do nosso conhecimento técnico, de nossas premissas sobre os indivíduos e todos os nossos objetivos, sejam eles explícitos ou não. Nas minas de carvão, a mesma tecnologia podia ser o suporte de diferentes formas de organização, com diferentes resultados econômicos e humanos. Além disso, o método composto de paredes longas ia contra outro dos fundamentos mais importantes da Administração Científica, cujos princípios têm realmente sustentado o modo de produção das empresas ao longo deste século, apesar da existência aparente de diferentes formas de organização. Ao contrário do que prega a Administração Científica, o projeto do trabalho não coube somente a especialistas. Embora não interferindo no projeto das máquinas, a concepção da organização do trabalho em Chopwell coube aos próprios mineiros, aos trabalhadores, a concepção foi então partilhada.

\section{OS FUNDAMENTOS DA ESCOLA SÓCIO-TÉCNICA}

Após essa brevíssima introdução histórica e da apresentação de alguns conceitos muito importantes, escolha organizacional e concepção partilhada, podemos tentar formar um quadro geral dos fundamentos da Escola Sócio-Técnica. A organização na perspectiva sócio-técnica é, antes de mais nada, um sistema aberto. Ela interage com o ambiente, é capaz de auto-regulação e possui a propriedade de eqüifinalidade, isto é, pode alcançar um mesmo objetivo a partir de diferentes caminhos e usando diferentes recursos. ${ }^{5}$ Ela é formada por dois subsistemas: o subsistema técnico - que são as máquinas, equipamentos, técnicos etc. e o subsistema social - que são os indivíduos e grupos de indivíduos, seus comportamentos, capacidades, cultura, sen- timentos e tudo de humano que os acompanha. O conceito de indivíduo e grupos inerente à abordagem sócio-técnica deriva de desenvolvimentos - em Psicologia Social, Psicanálise, Psicologia de Grupos e Sociologia - pouco anteriores ao seu próprio surgimento, principalmente devidos a Wilfred Bion, Kurt Lewin e Elliott Jaques. ${ }^{6}$

O mundo interno dos indivíduos é formado por seus instintos, inconsciente, capacidades inatas, superego, crenças e valores. A relação com o ambiente externo é controlada pelo seu ego ou consciente. Esses indivíduos apresentam diferenças também em termos de necessidades e expectativas. Assim, os modelos e estruturas de trabalho que os motivam não são únicos. Contudo, a Escola SócioTécnica considera que o comportamento das pessoas face ao trabalho depende da forma de organização deste trabalho e do conteúdo das tarefas a serem executadas, pois o desempenho das tarefas e os sentimentos a elas relacionados - responsabilidade, realização, reconhecimento etc. - são fundamentais para que o indivíduo retire orgulho e satisfação do seu trabalho. ${ }^{7}$

Ainda com relação ao subsistema social, é interessante e curioso destacar que os grupos possuem um nível de atividade equivalente ao inconsciente individual. Ao mesmo tempo em que se reúnem para o desempenho de uma tarefa explícita, as pessoas interagem em outro nível, tacitamente, levadas por poderosas forças psicológicas.

Então, o subsistema social, assim enfocado pela Escola Sócio-Técnica, e o subsistema técnico de determinado sistema de trabalho devem ser considerados particularmente e em suas relações e otimizados conjuntamente, para que os objetivos organizacionais sejam atingidos ao mesmo tempo em que alcançamos o desenvolvimento e a integração dos indivíduos. Isto quer dizer que é preciso projetar em conjunto o sistema social e a tecnologia particular ao caso. Nas palavras de Hugh Murray, outro pesquisador do Tavistock, otimização conjunta "significa definir a natureza das características fundamentais do sistema técnico e traduzir isto em tarefas e empregos que considerem as necessidades e características fundamentais dos seres humanos" ${ }^{8}$ 
Entretanto, essa otimização conjunta deve sempre buscar a consecução de um objetivo final - definido na abordagem sócio-técnica como tarefa primária - que, no caso das organizações industriais é a obtenção de lucros. Esta proposição, aparentemente positivista e simplista, é essencial para que a abordagem sócio-técnica não seja considerada como uma simples forma de experimentação social, mas uma forma de buscar, em última análise, o desenvolvimento de organizações mais eficazes. ${ }^{9}$

\section{OS GRUPOS SEMI-AUTONNOMOS}

foco principal dos estudos sáciotécnicos se dirige à organização dos sistemas produtivos no âmbito dos indivíduos e suas atividades. Devido à base conceitual, premissas e experiências vivenciadas pelos pesquisadores do Tavistock, uma forma específica de arranjo do trabalho é privilegiada: os grupos semiautônomos, dos quais as duplas de mineiros do primitivo hand-got system e os grupos de Chopwell são exemplos. Como poderíamos então delinear o que define um grupo semi-autônomo e fundamentar o porquê dessa preferência? Podemos iniciar dizendo que um grupo semi-autônomo ou auto-regulável se caracteriza pela responsabilidade coletiva frente a um conjunto de tarefas, onde o arranjo do trabalho é definido com a participação de seus próprios membros, permitindo o aprendizado de todas as tarefas e a rotação das funções, e facilitando uma interação cooperativa. O grupo semi-autônomo deve ainda ser responsável pelos recursos à sua disposiçāo e ter autoridade para utilizá-los.

A autonomia de um grupo semi-autônomo pode abranger: métodos de trabalho, escolha de líderes, distribuição de tarefas, definição de metas etc. É importante ressaltar que enquanto algumas dessas formas de autonomia têm impacto direto sobre a performance do grupo como no caso da definição do método outras simplesmente denotam o poder deste grupo frente à organização, como no caso da escolha de seu líder. ${ }^{10}$

Esse líder, ao contrário do que acontece na organização burocrática convencional, não está preocupado com o con- trole do trabalho dos operários, mas sim voltado a garantir as condições e os recursos necessários ao bom funcionamento do grupo. O líder para a Escola Sócio-Técnica está voltado para o ambiente e para facilitar a interface ambiente-grupo. Além disso, ele - o líder deve cuidar para que as relaçōes sociais no interior do grupo se mantenham bem estruturadas e voltadas principalmente à realização das tarefas, pois um grupo semi-autônomo é um grupo de tarefa e um grupo de vivência, isto é, um grupo que tem funções claras a executar e onde também existem relações sociais e afetivas.

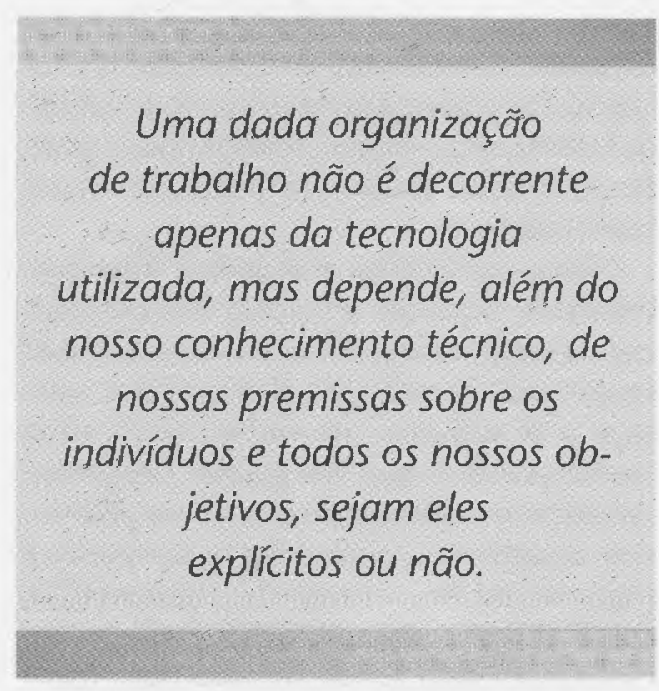

É interessante destacar que a manutenção de um mesmo grupo por longos períodos de tempo tende a cristalizar as relações sociais em detrimento da performance das tarefas, dificultando a elevação da produtividade e a adaptação a mudanças ambientais e tecnológicas. Essa particularidade do funcionamento dos grupos somada a outras fortes razões sociais e psicológicas, conscientes ou não, que atraem os indivíduos para grupos, faz com que seja conveniente projetar as organizações no sentido de captar essas forças e não lutar contra elas. Daí a escolha deste tipo de arranjo organizacional.

Contudo, as particularidades desse ou daquele grupo semi-autônomo - o número de membros, o grau de autonomia, a duração etc. - variam de acordo com a situação específica em que o grupo se in-
9. MILLER, E. J., RICE, A. K. Systems of organization. Londres: Tavistock, 1973.

10. GULOWSEN, J. A Measure of work-group autonomy. In: DAVIS, L. E., TAYLOR, J. C. Design of Jobs, Harmondsworth: Penguin Books, 1972; SUSMAN, G. I. Autonomy at work. Nova lorque: Praeger Publishers, 1976. 
11. EMERY, F. E., TRIST, E. L. The causal texture of organizational environments. Human Relations, v.18, n.2, p.21-32, 1965.

12. KINGDON, D. R. Matrix organization: managing information technologies. Londres: Tavistock, 1973.

13. TRIST, E. L. Referent organizations and the development of inter-organizational domains. Human Relations, v.36, n.3, p. 269-84, 1982 sere, com a tecnologia utilizada e sua evolução e com as demais demandas ambientais que vive a organização.

\section{O AMBIENTE E AS ESTRUTURAS ORGANIZACIONAIS}

Após alguns anos pensando nos sistemas de trabalho primários, os pesquisadores do Tavistock se aperceberam que esta adequação dos grupos semi-autônomos a diferentes situações não era, por si só, suficiente para que toda a organização se adaptasse às condições ambientais. No início da década de 60, Eric L. Trist e Frederick E. Emery se preocuparam em tentar definir qual o tipo de ambiente com que se defrontavam as organizações. Chamaram-no ambiente turbulento, caracterizado pela mutabilidade das demandas sociais, econômicas e políticas e pela rápida evolução das bases tecnológicas. ${ }^{11}$

Nessas condições ambientais ditas turbulentas, segundo a Escola Sócio-Técni$c a$, as organizações estruturadas nos moldes da burocracia tecnocrática passam a se adaptar ao ambiente de uma forma passiva, que incapacita progressivamente a organização a novas e profundas adaptações. Essa adaptação passiva pode se dar nas formas de segmentação, fragmentação e dissociação - que se caracterizam pela perda de foco dos objetivos e metas da organização - respectivamente relativos à perda de foco entre os níveis, ao longo do tempo e entre as divisões ou departamentos. Podemos fazer um paralelo entre a adaptação passiva das organizações com os mecanismos individuais de defesa psicológica, que resolvem um conflito apenas superficialmente, e apenas fazem com que o problema se agrave com o tempo.

A solução para uma satisfatória adaptação e sobrevivência das organizações em um ambiente turbulento é, para a Escola Sócio-Técnica, uma adaptação ativa. No âmbito do trabalho, como já dissemos, isto significa a adoção dos grupos semi-autônomos. No âmbito das organizações como um todo, a adaptação ativa implica a adoção de uma estrutura que permita a montagem e desmontagem dos grupos segundo as conveniências da situação, que é uma condição que existe nas organizações por projetos e na sua forma matricial. ${ }^{12}$

Porém, mesmo estas estruturas talvez não sejam suficientes para as organizações na adaptação adequada às demandas ambientais. No caso de projetos muito complexos, elas devem se associar a outras de modo a co-participarem em um trabalho conjunto formando o que os pesquisadores sócio-técnicos denominam matrizes organizacionais. Por outro lado, quando se defrontam com uma situação complexa, ou um sistema de problemas, como no caso de organizações em um distrito industrial ou organizações que pertençam ao sistema de saúde de determinada cidade ou país, as organizações envolvidas formam domínios inter-organizacionais, devendo se articular entre si ou mesmo através da criação de organizações que coordenem suas ações, chamadas de organizações referenciais. ${ }^{13} \mathrm{Co}$ locados assim os principais conceitos ligados à Escola Sócio-Técnica, devemos então considerar que sua abordagem engloba três diferentes níveis: o nível dos sistemas de trabalho primários, o nível da organização como um todo, e o nível chamado macrossocial, que abarca os sistemas de organizações. As respostas sócio-técnicas apontadas para cada um deles pressupõem então que deve haver um tratamento harmônico e coerente entre todos e, somente dessa forma, ganha a organização - podendo sobreviver e se adaptar, e ganham os indivíduos - podendo se integrar e se desenvolver.

\section{O PROJETO E A IMPLEMENTAÇÃO DE SISTEMAS SÓCIO-TÉCNICOS}

Um projeto organizacional sempre se dá com base em um conjunto de premissas, princípios e objetivos, quer eles sejam francamente admitidos ou não. Ao longo dos anos, os pesquisadores ligados à Escola Sócio-Técnica foram tentando operacionalizar os conceitos e fundamentos sucintamente apresentados até agora. Com isso, é possível vislumbrar atualmente os princípios que norteiam o projeto sócio-técnico e os atributos e características do trabalho, dos grupos e das organizações que devem decorrer desta adoção. Esses princípios e características devem estar na mente daqueles 
envolvidos na montagem desta organização nos moldes sócio-técnicos.

Dos princípios de projeto sócio-técnicos, para falar apenas nos mais importantes, se destacam os seguintes: compatibilidade, mínima especificação crítica e controle de variâncias. O princípio de compatibilidade destaca a necessidade de aderência entre o processo de mudança e seus objetivos. Em outras palavras, isto significa dizer que apenas um projeto participativo pode levar a uma organização participativa. Outro princípio essencial, da mínima especificação crítica, sustenta que o projeto do trabalho deve se ater a um mínimo de prescrições, reduzidas ao essencial para que os trabalhadores e grupos possuam a capacidade de resposta exigida à organização. $O$ princípio do controle de variâncias, por sua vez, indica que os desvios não programados de padrões ou procedimentos devem ser eliminados ou controlados o mais próximo possível dos pontos de origem.$^{14}$

A adoção destes princípios deve levar à construção de uma organização essencialmente diversa daquelas construídas em moldes burocráticos, tayloristas e fordistas. O trabalho deve possuir um conteúdo que demande as capacidades intelectuais e criativas dos indivíduos, permitir um aprendizado contínuo, gerar suporte social e reconhecimento e ter uma clara relação com a vida social dos operários e com os valores que eles partilham com a sociedade. As tarefas e grupos devem ser tais que possibilitem a visualização de um produto final e permitam a realimentação sobre os resultados, com diferenças mínimas de status e uma composiçăo heterogênea, multidisciplinar. Essas tarefas e grupos, assim como a própria estrutura organizacional, devem trabalhar no sentido das características discutidas dos grupos humanos, levando à cooperação, colaboração e comprometimento. A organização como um todo estará voltada à alta performance, à mudança contínua e ao contínuo aprendizado, à auto-regulação, ao estilo participativo e, muito importante citar, à concepção partilhada..$^{15}$

Quanto à implementação - seja em novas instalações, seja em unidades já em operação - deve se basear em metodolo- gias genéricas, em forma de roteiro, que apenas orientam àqueles responsáveis por sua coordenação e suporte. As condições essenciais para que a implementação da perspectiva sócio-técrica seja bem-sucedida são a existência de um fortíssimo apoio por parte da cúpula da organização e, principalmente, o sentimento disseminado de que a mudança é necessária à sobrevivência da organização.

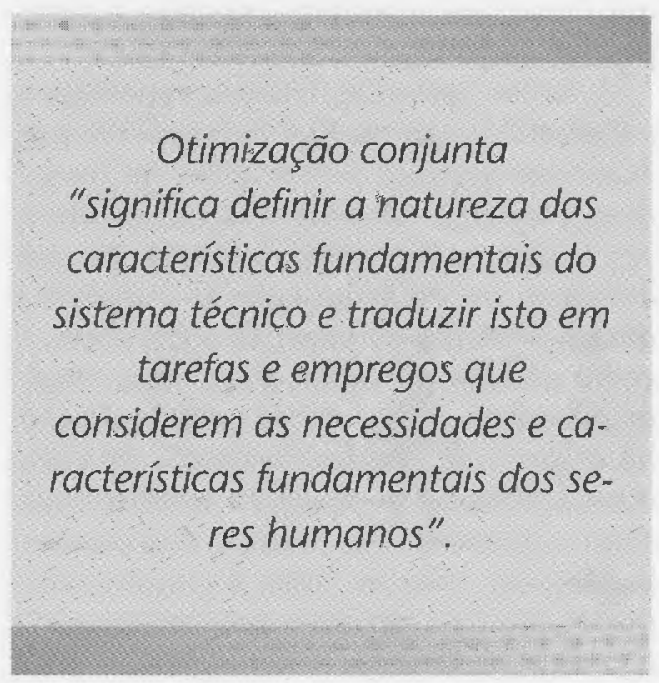

O projeto e implementação em si não escondem nenhum grande mistério. De modo muito, muito, resumido, podemos dizer que constituem ciclos, cada vez mais abrangentes de: formação de equipes, treinamento - com base em visitas, estudos de caso e aulas - na abordagem sócio-técnica, análise sócio-técnica e definição de instalações e métodos de trabalho, até que se incluam todos os funcionários e o mínimo essencial dos processos e métodos estejam definidos para a entrada e funcionamento. ${ }^{16}$

Isto se aplica às organizações industriais ou de serviços, às unidades de processamento contínuo ou não. O essencial é compreender, como diz o próprio Albert $B$. Cherns, que o projeto e a implementação baseados na perspectiva sóciotécnica pertencem, antes de mais nada, àqueles que terão seu trabalho e funções definidas nesse processo. ${ }^{17}$

Contudo, visto que a implementação da perspectiva sócio-técnica em sistemas produtivos que já se encontram em operação requer um cuidado maior - pelas disfunçōes que decisões equivocadas ou
14. CHERNS, A. B. Principles of Sociotechnical design revisited. Human Relations, v. 40, n.3, p. 153-62, 1987.

15. DAVIS, L. E. Evolving alternative organization designs: their sociotechnical bases. $\mathrm{Hu}$ man Relations, v. 30, n. 3, p. 261 73,1977 .

16. COLEMAN, G. D., JOHNSTON, C. S. Implementing the sociotechnical systems approach, including self-managing teams in a start-up organization. Quality \& Productivity Management, v.9, n.4, p.4-14, 1992.

17. CHERNS, A. B. The principles of sociotechnical design. Human Relations, v.29, n.8, p.783-92, 1976. 
fora de tempo podem provocar - William A. Pasmore desenvolveu, em 1988, uma metodologia que dá suporte a esse tipo de processo. ${ }^{18}$

\section{CONSEQÜÊNCIAS DA ADOÇÃO DA PERSPECTIVA SÓCIO-TÉCNICA}

Colocadas as bases, é necessário avaliarmos a conveniência e viabilidade da adoção da abordagem sócio-técnica. Por que deveríamos adotar - ou não - a perspectiva sócio-técnica?

A maior parte das lacunas conceituais e metodológicas da Escola Sócio-Técnica acabaram por ser preenchidas ao longo dessas quatro décadas e meia, desde o seu surgimento. A única observação que achamos necessária destacar - quando olhamos para a perspectiva sócio-técnica como uma resposta aos problemas organizacionais - é que existe uma limitação de escopo, de "poder de fogo". Embora consideremos a perspectiva sócio-técnica como necessária ao sucesso das organizações nos dias de hoje, a sua adoção, por si só, não garante que isto ocorra. Existem decisões estratégicas - por exemplo, aquelas relativas à escolha de nichos de mercado ou as soluções apontadas pela pesquisa e desenvolvimento da empresa - cuja qualidade das respostas depende muito de decisões tomadas na cúpula das organizações e assim ligam-se debilmente à adoção ou não do enfoque sócio-técnico. Assim, se considerarmos a adoção da perspectiva sóciotécnica como necessária ao sucesso organizacional, podemos dizer que ela não é suficiente.

As críticas mais interessantes encontradas na literatura reportam-se à afinidade da Escola Sócio-Técnica com as regras da sociedade capitalista. São aplicáveis à Escola Sócio-Técnica as críticas de Harry Braverman; relativas à limitação das mudanças àquelas que reduzem os custos e melhoram a posição frente à concorrência e ainda a dedicação a "descobrir os móveis do comportamento humano e a manipulação dele nos interesses patronais" ${ }^{19}$ Contudo, devemos dizer que esta manipulação, como diz André Gorz, depende da relação de forças que preside a introdução das mudanças..$^{20}$ Assim, a manipulação ocorre de- pendendo da posição - ativa ou passiva - dos trabalhadores no processo de mudança, sendo que os pesquisadores do Tavistock parecem desejar que esta participação seja a mais ativa possível. Quanto à primeira crítica de Harry Braverman, podemos dizer que a busca da eficiência organizacional é possivelmente a única forma de a perspectiva sóciotécnica não ser encarada como um experimento social e poder ser aceita pela sociedade contemporânea ocidental nos moldes em que se encontra estruturada, no chamado capitalismo monopolista.

De maneira mais abrangente, nós podemos tentar visualizar a conveniência $e$ as conseqüências da adoção e difusão do enfoque sócio-técnico segundo três ópticas distintas: a da esfera organizacional, a da esfera humana e a da esfera social. Uma análise da Escola Sócio-Técnica do ponto de vista organizacional é aquela que mais interessa aos dirigentes e executivos das empresas e se refere aos resultados mensuráveis do desempenho dos funcionários e da organização. Feita uma ressalva quanto às limitações das amostras utilizadas em revisões e avaliações - decorrentes da tendência à divulgação das experiências bem-sucedidas e às várias amplitudes de mudança encontradas nos diferentes casos -, podemos sintetizar como principais resultados da adoção da perspectiva sócio-técnica os seguintes:

1. aumentos significativos de produtividade (e qualidade), não de 5 a $10 \%$, mas em geral de 50 a $100 \%$;

2. redução de taxas de absenteísmo;

3. maior produtividade onde os grupos têm mais autonomia;

4. maior adequação a unidades com cerca de 200 a trezentos funcionários;

5. encontramos ainda uma maior aplicação em processos contínuos, embora não sejam encontradas limitações para processos discretos ou nos setores de serviços;

6. e, por último, constatou-se que não existem restrições de ordem cultural.

A análise da Escola Sócio-Técnica, do ponto de vista do ser humano, é tão ou mais importante quanto a do ponto de vista organizacional. A adoção da pers- 
pectiva sócio-técnica tende, relativamente à adoçäo dos princípios da burocracia taylorista-fordista, a provocar um maior desenvolvimento e integração, psicológica e social, dos indivíduos. Tende ainda a orientar a produção e o consumo segundo as necessidades e valores dos indivíduos. Ao mesmo tempo em que privilegia uma qualificação não fundamentada em saber formal ou na automação, essa perspectiva leva à participação e a uma autonomia responsável, baseada em conhecimento técnico e relacionamento humano.

A adoção da perspectiva sócio-técnica leva ainda à reduçăo dos níveis de alienação, não no sentido da posse dos meios de produção ou dos produtos, mas nos sentidos apontados por Robert Blauner de: impotência, ausência de sentido, isolamento e auto-alienação. ${ }^{21}$ Além disso, permite um maior desenvolvimento de habilidades e potencialidades humanas como: iniciativa, criatividade, autonomia, responsabilidade, multifuncionalidade, confiança, solidariedade, reconhecimento etc. Contudo, como o ser humano não se restringe apenas a essas facetas, uma situação ideal passa pela adoção do enfoque sócio-técnico e pela redução da jornada de trabalho, criando-se assim embasamento e tempo para que outras habilidades e potencialidades nảo contemplàdas no período de trabalho possam se desenvolver.

Por último, é necessário tentarmos esboçar uma análise da perspectiva sóciotécnica do ponto de vista social. Isto significa tentar compreender se essa abordagem tem se difundido e, por outro lado, se esta difusão extrapola os limites das fábricas. Quanto ao primeiro ponto, da difusão da perspectiva sócio-técnica, é possivel avaliar o seguinte: quando nós observamos a evolução dos padrões de organização do trabalho e de estruturação intra e interempresas nos últimos anos, é surpreendente o número crescente de pontos em comum que estas formas de organização têm com a Escola Sócio-Técnica. Isto transparece nos casos relatados, nos trabalhos publicados e mesmo em novas teorias que vêm surgindo. Essa aproximaçāo crescente não respeita fronteiras, dando-se, embora com diferentes ênfases e particularidades, nos Estados Unidos, Europa e Japão.
A busca pela participação ativa dos trabalhadores e a estruturação de organizações matriciais e matrizes organizacionais é mais e mais intensa a cada ano que passa. Se considerarmos historicamente o surgimento e consolidação dessa filosofia que foi aqui apresentada, ressaltando as datas em que os conceitos e idéias foram veiculados e difundidos - por exemplo, década de cinqüenta para os grupos semi-autônomos, década de sessenta para ambiente turbulento e adaptação ativa -, teremos então uma noção mais precisa do pioneirismo e do mérito de tais idéias.

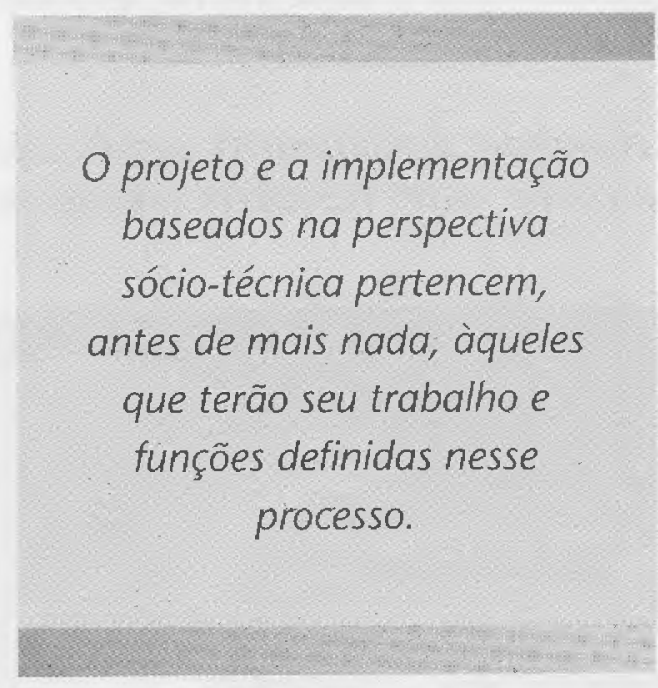

A perspectiva sócio-técnica se vincula principalmente ao que o próprio Eric Trist chama de democracia no local de trabalho. Sua adoção implica mudanças qualitativas na relação indivíduo/organização. Além de se apresentar como uma das estratégias mais eficazes para a sobrevivência e desenvolvimento das organizações nesse turbulento final de século, a perspectiva sócio-técnica acena com possibilidades de integração e desenvolvimento - social, psicológico e técnico para aqueles envolvidos nos processos de mudança e condução dessas "novas fábricas". Integraçäo e desenvolvimento esses que serão tanto maiores quanto maiores forem a iniciativa e a participação dos trabalhadores nesses processos, fazendo valer suas necessidades e anseios e buscando uma forma de organização do trabalho verdadeiramente fundamentada em valores humanos. $\square$
21. BLAUNER, R. Alienation and freedom: the factory worker and his industry. Chicago: University of Chicago Press, 1964 